\section{The waterpipe: an emerging global epidemic in need of action}

\author{
Kenneth D Ward
}

The story has been told many times: waterpipe, a centuries-old tobacco use method in which smoke is passed through water before being inhaled, probably originated on the Indian subcontinent and southeast Asia. Over the years, it spread and became popular in the Middle East. During most of the 20th century, it seemed that waterpipe's heyday had passed, in favour of easy-to-use types of tobacco such as cigarettes. Its use was not even registered in the expanding body of global tobacco surveillance systems. The medical and public health literatures made little note of it: Rakower and Fatal's ${ }^{1}$ examination of lung cancer mortality rates by ethnic groups in Jerusalem that differed in their use of waterpipe, appearing in the British Journal of Cancer, was the first notice of waterpipe in Medline in 1962, and almost 20 years were to pass before any additional studies were to appear. But things suddenly changed in the 1990s: upticks in use were observed in the Middle East, especially among teenagers and young adults. This was mostly fuelled by the invention of flavoured and easier-to-use tobacco, a growing café culture in the Middle East, and expanding internet availability and globalisation. As a result, waterpipe use has snowballed globally at the start of the 21st century.

Tobacco Control published the first review of waterpipe's global spread and health effects in 2004, ${ }^{2}$ noting the scant but steadily increasing research base, and the potential for waterpipe to upend successes in global tobacco control. A decade later, that forecast has come true. In this supplement, Maziak et $a l^{3}$ note that the "global evolution of this smoking habit has exceeded worst predictions." In several Middle Eastern nations, the waterpipe has quickly replaced cigarettes as the most popular method of tobacco use among youth, and in several other parts of the world, it is becoming second only to cigarettes. ${ }^{3}$ Among US high school students, cigarette use has dropped 33\% during the last decade, while use of noncigarette combustible tobacco products,

Correspondence to Kenneth D Ward, University of Memphis School of Public Health, Syrian Center for Tobacco Studies, Memphis, TN 38152, USA;kdward@ memphis.edu including waterpipe, has increased by $123 \%{ }^{4}$

In the aftermath of this re-emerging strain in the global tobacco epidemic, there has been an explosion of interest in waterpipe, and several hundred scientific papers about it have now been indexed in PubMed. The seven reviews in this Special Supplement comprehensively document the tremendous progress that has been made during the last decade in understanding waterpipe's toxicity, epidemiology, addictiveness, health consequences to users and bystanders, and policy implications.

Ten years ago, little data were available to challenge the pervasive notion that waterpipe smoking is a relatively safe pastime compared with cigarettes. Such misinformation was propagated by misleading descriptors on waterpipe tobacco packages about its supposedly low tar and nicotine content, absent or weak health warnings, and the belief that whatever harmful constituents waterpipe smoke does contain are 'filtered' out by water. Careful work by several groups, however, has dispelled these false claims and misperceptions. Shihadeh et $a l^{5}$ synthesise now sizeable literatures from analytic and human biomarker studies demonstrating that waterpipe smoke is a substantial inhalation hazard. It is a biologically active respirable submicron aerosol that induces cellular responses leading to chronic obstructive pulmonary disease and arterial disease. Like cigarettes, waterpipe delivers nicotine, carbon monoxide and 'tar' to users. From this 'tar', 82 toxicants have been quantified in waterpipe tobacco smoke to date, including polyaromatic hydrocarbons, tobacco-specific nitrosamines, carbonyl compounds and volatile organic compounds.

Given these similarities in toxicant exposure, it is not surprising that a growing literature indicates that waterpipe smoking is associated with the same extensive laundry list of adverse health effects as cigarette smoking. In the short term, waterpipe smoking increases heart rate and blood pressure, stimulates inflammatory processes and impairs pulmonary function. An additional short-term burden of waterpipe smoke, distinct from cigarettes due to the use of charcoal to heat waterpipe, is the risk of carbon monoxide poisoning. Although high-quality studies on waterpipe's long-term effects are still scarce, growing evidence indicates that the chronic health effects of waterpipe smoking can mimic those of cigarette smoking, including bronchitis, emphysema, lung, gastric and oesophageal cancers, periodontal disease, obstetrical complications and low birth weight, osteoporosis, obesity and metabolic syndrome, and mental health problems. ${ }^{6}$

Articles in this Special Supplement by Aboaziza, Akl, Jawad, Maziak, and their colleagues, ${ }^{3-9}$ make it clear that determinants at multiple levels are driving this epidemic. Waterpipe smoke delivers substantial amounts of nicotine. For many users, this exposure may result in dependence, revealed by urges to smoke and other withdrawal symptoms when they abstain, relief of these symptoms when they smoke and difficulty quitting, even when motivated to do so. ${ }^{7}$ While these features are remarkably similar to those exhibited by dependent cigarette smokers, waterpipe dependence may have unique associative components (eg, specific sights, sounds and smells, and the highly social and ritualistic nature of its use) and may be marked by the transition from social to solitary use. These differences may be important in preventing and treating its use.

Individual-level and interpersonal-level determinants of waterpipe smoking have received the most attention to date. Although use patterns are still evolving, waterpipe use clusters among younger age groups, the educated and males. ${ }^{3}$ In the absence of the stigma attached to cigarette smoking by females in traditional Arab societies, its use among girls also has been increasing. In addition, waterpipe use is much more common among cigarette smokers, raising concerns about the 'collision of two epidemics' and expanding tobacco-related morbidity and mortality. Fuelled by misperceptions about its health effects and addictive potential, as well as a mass media environment that emphasises a global youth culture, waterpipe use is seen around the world as a socially acceptable, fashionable, relatively harmless and inexpensive way to relax with friends. ${ }^{8}$

These determinants have conspired in extremely lax regulatory environments around the globe to escalate waterpipe use. Reviewing tobacco-related legislative documents of 62 countries, Jawad et al ${ }^{9}$ show that most do not specifically address waterpipe regulation and, at best, rely on 'generic' tobacco definitions to address waterpipe use. Unfortunately, as noted by 
the authors, "Generic laws are not sensitive to the particularities and challenges inherent in regulating (waterpipe tobacco smoking) as well as associated waterpipe tobacco products and accessories" (p. 5). So, for example, in the USA the Family Smoking Prevention and Tobacco Control Act bans flavoured cigarettes but not flavoured waterpipe tobacco. And although three-fourths of the 100 largest cities in the USA prevent cigarette smoking in bars, nearly $90 \%$ of these cities exempt 'hookah bars'. ${ }^{10}$ Even when waterpipe tobacco is specifically mentioned in tobacco control frameworks, guidance is not provided to deal with such issues as the ever-expanding proliferation of producers, advertisers and importers, and the vast array of apparatuses, supplies, tobacco flavours and packaging modes that challenge regulatory efforts. The awkward fit of the WHO's Framework Convention on Tobacco Control for waterpipe control has been repeatedly emphasised. $^{11}$

A grain of hope for regulatory efforts is the impressive work done to date to quantify the burden of waterpipe toxicant exposure experienced by non-smokers. Kumar et $a l^{12}$ reviewed 11 studies that assessed air quality of hookah bars or health effects of secondhand exposure to waterpipe smoke. For the majority of venues, concentrations of particulate matter were in the unhealthy to hazardous range, according to Environmental Protection Agency standards, and exceeded levels commonly found in venues that allow cigarette smoking. The air in hookah bars also contains significant amounts of aromatic hydrocarbons, carbon monoxide, nicotine and trace metals. Two studies from Lebanon, ${ }^{13} 14$ included in this review, found that exposed non-smokers were more likely than non-exposed individuals to experience respiratory symptoms such as wheezing, nasal congestion and chronic cough. Hookah bar employees, who often are exposed to toxic air for extended amounts of time, are likely to be at especially high risk. Using a strategy that was successful at turning the tide of public opinion in favour of clean air laws to limit exposure to cigarette smoking, these waterpipe studies should be used to persuade policy-makers that waterpipe smoking hurts non-smokers, who need to be protected through proper regulations.
Efforts to control and regulate waterpipe use are emerging, but the battle is just beginning. Two recent international conferences on waterpipe tobacco research have issued declarations recommending immediate action on several fronts to get ahead of this epidemic, including banning of flavoured waterpipe tobacco, specific inclusion of waterpipe smoking in clean indoor air regulations, and elimination of waterpipe tobacco product advertising and marketing.

Given the recentness of the waterpipe story, it is hard to predict how it will unfold in the future. As it stands, we now have a good knowledge base of its potential harm to users and bystanders, as well as its addictive nature. New evidence indicates waterpipe's ability to hook young people on nicotine and deliver them to cigarettes. ${ }^{15}$ Waterpipe also may precipitate relapse after quitting cigarette smoking. ${ }^{16} 17$ This Special Issue, strategically released in time for the 16th World Conference on Tobacco or Health to be held for the first time in the Middle East (Abu Dhabi), gives hope that the evolving science of waterpipe tobacco smoking can be marshalled to curtail this epidemic, hopefully more quickly and efficiently than the several decades it took to confront the cigarette epidemic.

\section{Competing interests None.}

Provenance and peer review Commissioned; internally peer reviewed.
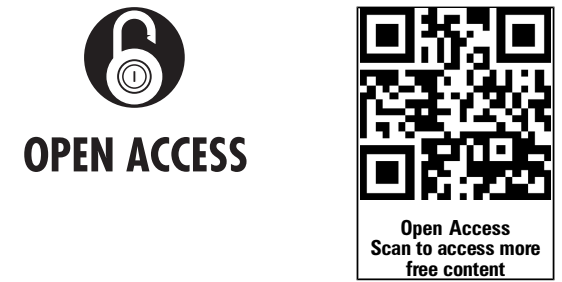

Open Access This is an Open Access article distributed in accordance with the Creative Commons Attribution Non Commercial (CC BY-NC 4.0) license, which permits others to distribute, remix, adapt, build upon this work non-commercially, and license their derivative works on different terms, provided the original work is properly cited and the use is noncommercial. See: http://creativecommons.org/licenses/ by-nc/4.0/

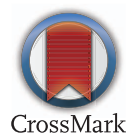

To cite Ward KD. Tob Control 2015:24:11-i2.
Received 5 January 2015

Accepted 6 January 2015

Published Online First 24 January 2015

Tob Control 2015:24:i1-i2.

doi:10.1136/tobaccocontrol-2014-052203

\section{REFERENCES}

1 Rakower J, Fatal B. Study of narghile smoking in relation to cancer of the lung.Br J Cancer 1962;16:1-6.

2 Maziak W, Ward KD, Afifi Soweid RA, et al. Tobacco smoking using a waterpipe: a re-emerging strain in a global epidemic. Tob Control 2004;13:327-33.

3 Maziak W, Ben Taleb Z, Bahelah R, et al. The global epidemiology of waterpipe smoking. Tob Control 2015;24:i3-12.

4 Centers for Disease Control and Prevention (CDC). Consumption of cigarettes and combustible tobacco -United States, 2000-2011. Morb Mortal Wkly Rep 2012:61:565-9.

5 Shihadeh A, Saliba N, Schubert J, et al. Toxicant properties, physical properties, and biological activity of waterpipe tobacco smoke and its tobacco-free alternatives. Tob Control 2015:24:i22-30.

6 El-Zaatari ZM, Chami HA, Zaatari GS. Health effects associated with waterpipe smoking. Tob Control 2015;24:i31-43.

7 Aboaziza E, Eissenberg T. Waterpipe tobacco smoking: what is the evidence that it supports nicotine/tobacco dependence? Tob Control 2015;24: i44-53.

8 Akl E, Ward K, Bteddini D, et al. The allure of the waterpipe: a narrative review of factors affecting the epidemic rise in waterpipe smoking among young persons globally. Tob Control 2015:24:113-21.

9 Jawad M, El Kadi L, Mugharbil S, et al. Waterpipe tobacco smoking legislation and policy enactment: a global analysis. Tob Control 2015;24:160-65.

10 Primack BA, Hopkins M, Hallett $C$, et al. US health policy related to hookah tobacco smoking. Am J Public Health 2012;102:e47-51.

11 Maziak W, Nakkash R, Bahelah R, et al. Tobacco in the Arab world: old and new epidemics amidst policy paralysis. Health Policy Plan 2014:29:784-94.

12 Kumar SR, Davies S, Weitzman M, et al. A review of air quality, biological indicators and health effects of second-hand waterpipe smoke exposure. Tob Control 2015;24:154-59.

13 Tamim H, Musharrafieh U, El Roueiheb Z, et al. Exposure of children to environmental tobacco smoke (ETS) and its association with respiratory ailments. J Asthma 2003;40:571-6.

14 Zeidan RK, Rachidi S, Awada S, et al. Carbon monoxide and respiratory symptoms in young adult passive smokers: a pilot study comparing waterpipe to cigarette. Int J Occup Med Environ Health 2014:27:571-82.

15 Jaber R, Khader $Y$, Mzayek $F$, et al. Predictors of waterpipe smoking progression among a school-based sample of adolescents in Irbid, Jordan: a three-year longitudinal study. Under review.

16 Asfar T, Vander Weg M, Maziak W, et al. Outcomes and adherence in Syria's first smoking cessation trial Am J Health Behav 2008:32:146-56.

17 Hammal F, Mock J, Ward KD, et al. A pleasure among friends: how narghile (waterpipe) smoking differs from cigarette smoking in Syria. Tob Control 2008; $17: \mathrm{e3}$ 